\title{
Responsabilidades do profissional enfermeiro na hipotermia terapêutica pós-parada cardiorrespiratória em terapia intensiva: revisão da literatura
}

O Objetivo deste trabalho é identificar as responsabilidades do enfermeiro na Hipotermia Terapêutica Pós-Parada Cardiorrespiratória (PCR) em pacientes internados em Unidades de Terapia Intensiva. A revisão de literatura foi realizada entre abril e maio de 2021, buscando responder a questão norteadora: "Quais as responsabilidades e cuidados do enfermeiro diante a hipotermia terapêutica nas Unidades de Terapia Intensiva (UTI) em pacientes pós-PCR?". Dez artigos atenderam os critérios de elegibilidade, sendo 9 publicados no idioma inglês e apenas 1 em português. Os artigos selecionados foram publicados na Literatura Latino-americana e do Caribe em Ciências da Saúde (LILACS), na Base de Dados de Enfermagem (BDENF) e no Sistema Online de Busca e Análise de Literatura Médica (MEDLINE). A Hipotermia Induzida (HI) se mostrou eficaz em pacientes submetidos a temperaturas entre $33^{\circ} \mathrm{C}$ e $36^{\circ} \mathrm{C}$, onde $\mathrm{O}$ resfriamento deve acontecer de $12 \mathrm{~h}$ às $24 \mathrm{~h}$ após a PCR. Benefícios na melhora da função neurológica, diminuição da demanda cerebral e mortalidade hospitalar foram observados. Responsabilidades do enfermeiro na monitorização rigorosa dos sinais vitais, exames laboratoriais e parâmetros hemodinâmicos. A terapêutica apresenta pontos positivos, porém, sua aplicação necessita da produção técnico-científica e educação permanente, além do treinamento de equipe, com base na eficácia e veracidade da $\mathrm{HI}$, necessitando ampliação da sua prática.

Palavras-chave: Enfermagem; Hipotermia Induzida; Parada Cardíaca.

\section{Responsabilities of the nurse professional in the post cardiopulmonary arrest therapeutic hipothermia in intensive care: literature review}

The objective is to identify the responsibilities of nurses in Post Cardiopulmonary Arrest Therapeutic Hypothermia (PCR) in patients hospitalized in Intensive Care Units. The Literature review was carried out between April and May 2021, seeking to answer the guiding question: "What are the responsibilities and care of nurses in the face of therapeutic hypothermia in the Intensive Care Units (ICU) in post-CPA patients?". Ten articles met the eligibility criteria, 9 published in English and only 1 in Portuguese. The selected articles were published in the Latin American and Caribbean Literature on Health Sciences (LILACS), in the Nursing Database (BDENF) and in the Online System for Search and Analysis of Medical Literature (MEDLINE). Induced Hypothermia (HI) proved to be effective in patients submitted to temperatures between $33^{\circ} \mathrm{C}$ and $36^{\circ} \mathrm{C}$, where cooling should take place from $12 \mathrm{~h}$ to $24 \mathrm{~h}$ after PCR. Benefits in improving neurological function, decreased brain demand and hospital mortality were observed. Nurse's responsibilities in the rigorous monitoring of signs, laboratory tests and parameters. The therapy has positive points, however, its application requires technical-scientific production and permanent education, in addition to team training, based on the effectiveness and veracity of $\mathrm{HI}$, requiring expansion of its practice.

Keywords: Nursing; Induced Hypothermia; Cardiac Arrest.

Topic: Enfermagem Geral

Reviewed anonymously in the process of blind peer
Received: 16/06/2021

Approved: 14/07/2021
Ana Luiza Rosa Manoel (ic)

Universidade de Sorocaba, Brasil

http://lattes.cnpq.br/3532644968982555

http://orcid.org/0000-0002-0541-8671

analuizarsm96@gmail.com

Rafael Henrique Lopes (ib)

Universidade de Sorocaba, Brasil

http://lattes.cnpq.br/4395322971584109

http://orcid.org/0000-0003-0369-2463

rafael-06henrique@hotmail.com

Victória Sofia Moreira Marques Penteado (D)

Universidade de Sorocaba, Brasil

http://lattes.cnpq.br/5444418254091968

http://orcid.org/0000-0001-5297-1261

vicmaques@gmail.com

d

DOI: $10.6008 / C B P C 2236-9600.2021 .003 .0007$

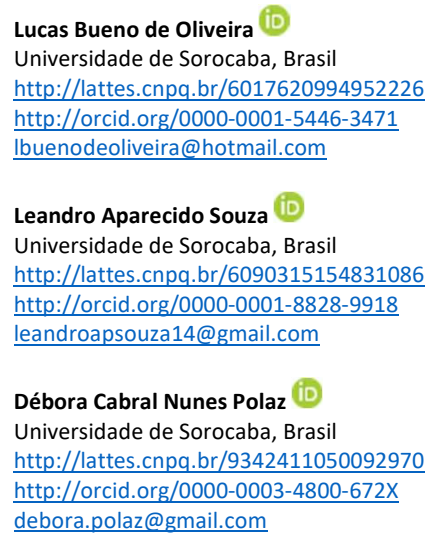

Clayton Gonçalves de Almeida

Universidade de Sorocaba, Brasil

http://lattes.cnpq.br/6493791537446598

http://orcid.org/0000-0003-2959-3965

cgalmeida11@gmail.com

Referencing this:

MANOEL, A. L. R.; LOPES, R. H.; PENTEADO, V. S. M. M.; OLIVEIRA, L. B.; SOUZA, L. A.; POLAZ, D. C. N.; ALMEIDA, C. G.. Responsabilidades do profissional enfermeiro na hipotermia terapêutica pós-parada cardiorrespiratória em terapia intensiva: revisão da literatura. Scire Salutis, v.11, n.3, p.46-52, 2021. DOI:

http://doi.org/10.6008/CBPC2236-9600.2021.003.0007 


\section{INTRODUÇÃO}

O comprometimento da contratilidade miocárdica em conjunto com a interrupção da circulação sanguínea promove cessação súbita e inesperada das funções vitais, risco de isquemia em neurônios e dano cerebral irreversível (PEDROSA et al., 2019). A parada cardiorrespiratória (PCR) é um evento de emergência médica com alto custo no tratamento da terapêutica em pacientes pós-PCR. A lesão neurológica depende do grau de hipoxemia associada ao tecido cerebral, bem como do seu tempo de intervenção. A supressão completa do fluxo sanguíneo entre 5 a 10 minutos já pode se considerar como indicativo de dano cerebral permanente. Nesse contexto, a hipotermia terapêutica (HT) tem demonstrado ser um tratamento eficaz em reduzir o dano isquêmico cerebral produzido durante os diversos agravos neurológicos. A HT reduz a demanda cerebral de oxigênio, promovendo proteção contra a isquemia (CASTRO, 2014).

A hipotermia induzida (HI) é uma técnica que vem sendo utilizada para minimizar os efeitos danosos da diminuição do suprimento sanguíneo durante a parada cardiorrespiratória. Apesar de ser um método de fácil utilização e baixo custo, possui indicações específicas e cuidados intensivos durante sua realização (ROCHA et al., 2017). Dentre os benefícios na aplicação da HT, a redução da demanda cerebral de oxigênio, pressão intracraniana e permeabilidade vascular são os benefícios mais observados (PEDROSA et al., 2019).

Essa prática terapêutica se resume na redução da temperatura corpórea de pacientes comatosos com Retorno da Circulação Espontânea (RCE), sendo este mantido constantemente entre 32 a $36^{\circ} \mathrm{C}$ por 24 horas (ABREU et al., 2011; AHA, 2015). As técnicas de resfriamento corporal podem ser realizadas de diversas formas, sendo utilizados fluidos intravenosos, com especial preferência pelo soro Ringer Lactato à $4^{\circ} \mathrm{C}$, Resfriamento por Lavagem Peritoneal e Pleural, e em alguns casos pode ser feito o Resfriamento Extracorpóreo do Sangue, sendo este o método mais rápido para que se alcance baixas temperaturas (CORREA et al., 2018). A literatura científica nos mostra que o resfriamento deve ser iniciado o mais breve possível após o retorno da circulação espontânea para se obtiver os melhores resultados funcionais, porém parece haver benefício do início da terapia mesmo quando seu início é retardado em até 6 horas após o evento (PEDROSA et al., 2019).

São identificadas quatro fases da hipotermia terapêutica, sendo estas: a fase de identificação do paciente, conhecer o histórico do indivíduo para que seja possível utilizar os critérios de exclusão da HT, a fase da indução da hipotermia , sendo caracterizada pela indução da hipotermia de modo não invasivo ou invasivo, visando atingir cerca de 32 a 34 ํ $\mathrm{C}$, a fase da manutenção da hipotermia, manter a temperatura atingida, em sedação e a analgesia e a fase de reaquecimento do paciente que corresponde ao reaquecer de forma ativa ou passiva até que o mesmo atinja temperaturas entre 35 a 37 으 num período de 12 horas (CASTRO, 2014).

Tal conduta terapêutica pode apresentar inúmeras complicações potenciais em que o enfermeiro, o profissional que assiste o paciente e como gestor do cuidado, deve ter percepção para identificar estas possíveis complicações, pois a assistência prestada deverá ser intermitente e contínua, bem como abranger todo o contexto de risco que esse paciente possa ter (PEDROSA et al., 2019). Este artigo tem por objetivo 
identificar o manejo do enfermeiro e suas responsabilidades diante a hipotermia terapêutica pós-PCR em pacientes internados na Unidade de Terapia Intensiva (UTI) através da análise e revisão da literatura.

\section{METODOLOGIA}

Trata-se de uma pesquisa de revisão da literatura, dos quais os artigos que constituíram o estudo abordaram a identificação do manejo, responsabilidades e cuidados do enfermeiro intensivista na HT pósPCR em pacientes internados em unidade de terapia intensiva. Para a busca dos artigos foram utilizadas as bases de dados: Literatura Latino-americana e do Caribe em Ciências da Saúde (LILACS), Base de Dados de Enfermagem (BDENF) e o Sistema Online de Busca e Análise de Literatura Médica (MEDLINE), por meio da plataforma Biblioteca Virtual em Saúde (BVS), a partir dos descritores: Enfermagem, Hipotermia Induzida e Parada Cardíaca.

Na pesquisa foram incluídos artigos originais, que responderam aos objetivos do estudo, publicados entre o período de 2011 a 2021, nos idiomas inglês e português. A pesquisa foi ampliada para os últimos 10 anos devido à escassez na literatura nos últimos 5 anos. $O$ presente estudo teve como ênfase a seguinte pergunta norteadora: "Qual o manejo, responsabilidades e cuidados do enfermeiro intensivista na hipotermia terapêutica na UTI em pacientes pós-PCR"?

Os critérios de exclusão foram definidos a partir dos estudos que não contemplavam ao objetivo da pesquisa, dissertações ou teses, trabalhos incompletos e os que foram publicados anteriormente a 2011. A busca resultou em 54 artigos levantados, dos quais, após análise, foram descartados 44, que não atendiam aos critérios de inclusão, sendo selecionados 10 artigos. A coleta dos dados ocorreu entre abril e maio de 2021 e para a consolidação do estudo seguiu-se as etapas: escolha do tema, levantamento bibliográfico preliminar, formulação do problema, elaboração do plano provisório do assunto, busca de fontes, leitura do material, fichamento, organização lógica do assunto e por fim a redação do texto.

A análise ocorreu a partir da realização de leitura sistemática dos artigos, onde foram retiradas as ideias centrais de cada estudo, sendo os resultados apresentados, em forma de quadro. Foram analisadas 5 categorias dos artigos: Título, ano de publicação, autores, objetivo e resultados.

\section{RESULTADOS E DISCUSSÃO}

Os 10 artigos selecionados e analisados neste estudo estão apresentados no quadro 01. Após análise dos estudos selecionados foi evidenciado que, segundo Wannemacher et al. (2017) e Erb et al. (2012), quando a HT é implementada e for atingida a temperatura corporal recomendada, os pacientes atingem resultados neurológicos mais favoráveis. Beseda et al. (2014) cita que os benefícios da indução da hipotermia, são: a prevenção de perda de neuroprotetores endógenos e o bloqueio de cascatas de lesão secundária. Ainda sobre os benefícios, Hall (2015) ressalta a redução da taxa metabólica cerebral e da demanda por oxigênio, bem como pressão intracraniana, além da excitatória produção de neurotransmissores e radicais livres de formação e acumulação. 
Quadro 1: Caracterização da produção científica analisada segundo título do estudo, anos de publicação, autores, objetivo e resultados, Sorocaba, SP, 2021

\begin{tabular}{|c|c|c|c|c|}
\hline Título do estudo & $\begin{array}{c}\text { Ano de } \\
\text { Publicação }\end{array}$ & Autores & Objetivo & Resultados \\
\hline $\begin{array}{l}\text { A verdade nua e } \\
\text { crua sobre o } \\
\text { gerenciamento de } \\
\text { temperatura } \\
\text { direcionada à } \\
\text { parada cardíaca: } 33 \\
{ }^{\circ} \mathrm{C} \text { vs. } 36^{\circ} \mathrm{C}\end{array}$ & 2020 & Kinppa et al. & $\begin{array}{l}\text { Contribuir na discussão da escolha } \\
\text { da temperatura (33ํ vs } 36 \text { ํ), } \\
\text { apresentando prós e contras da } \\
\text { hipotermia induzida no } \\
\text { tratamento de pacientes pós } \\
\text { parada cardíaca. }\end{array}$ & $\begin{array}{l}\text { Ambas as temperaturas são eficazes a } \\
\text { depender do quadro em que o } \\
\text { paciente se encontra para definir a } \\
\text { melhor opção. } \\
\text { - Independente da temperatura, } \\
\text { tremores ou convulsões podem } \\
\text { acontecer, estando na } \\
\text { responsabilidade da enfermagem a } \\
\text { monitorização para estes tipos de } \\
\text { complicações. } \\
\text { - Alterar o protocolo do nível } \\
\text { esperado é algo que pode ser } \\
\text { considerado de acordo com a } \\
\text { resposta do paciente em relação à } \\
\text { terapêutica utilizada. }\end{array}$ \\
\hline $\begin{array}{l}\text { Gerenciamento de } \\
\text { temperatura para } \\
\text { um resultado } \\
\text { melhorado }\end{array}$ & 2018 & Carwel & $\begin{array}{l}\text { Identificar evidências atuais e } \\
\text { barreiras contra o protocolo de } \\
\text { hipotermia induzida para } \\
\text { enfermeiros em cuidados } \\
\text { intensivos de pacientes com } \\
\text { parada cardíaca. }\end{array}$ & $\begin{array}{l}\text { Devido a alta variação entre os } \\
\text { estudos em relação a falta de } \\
\text { consistência com as características } \\
\text { dos participantes de inclusão e } \\
\text { exclusão, duração da terapia, } \\
\text { mecanismo de resfriamento, } \\
\text { temperatura alvo, taxa de } \\
\text { resfriamento e reaquecimento e } \\
\text { cronograma para avaliação de } \\
\text { resultados neurológicos e de } \\
\text { sobrevivência, fica evidente que não } \\
\text { foi possível manter protocolos exatos } \\
\text { para a hipotermia induzida. }\end{array}$ \\
\hline $\begin{array}{l}\text { Gerenciamento de } \\
\text { temperatura alvo } \\
\text { em cuidados de } \\
\text { enfermagem }\end{array}$ & 2018 & Keeble at al. & $\begin{array}{l}\text { Relatar a hipotermia terapêutica } \\
\text { em nível extra-hospitalar. }\end{array}$ & $\begin{array}{l}\text { Pré-resfriamento de temperatura no } \\
\text { transporte extra-hospitalar com } \\
1.500 \mathrm{ml} \text { de solução salina gelada ao } \\
\text { longo de } 30 \text { minutos, se a } \\
\text { temperatura }>33,5^{\circ} \mathrm{C} \text {, infusão de mais } \\
500 \mathrm{~mL} \text {, repetindo até } 3 x \text { se } \\
\text { necessário, no limite máximo de } \\
\text { 3.000ml. Paralisando paciente até } \\
\text { atingir a temperatura desejada. }\end{array}$ \\
\hline $\begin{array}{l}\text { Hipotermia } \\
\text { terapêutica: efeitos } \\
\text { adversos, } \\
\text { complicações e } \\
\text { cuidados de } \\
\text { Enfermagem }\end{array}$ & 2018 & Corrêa et al. & $\begin{array}{l}\text { Conhecer os efeitos adversos e } \\
\text { complicações vivenciadas pela } \\
\text { equipe de saúde e os cuidados de } \\
\text { enfermagem na aplicação da } \\
\text { hipotermia terapêutica. }\end{array}$ & $\begin{array}{l}\text { Dentre os efeitos adversos, foram } \\
\text { destacados tremores, bradicardia, } \\
\text { hipotensão e complicações como } \\
\text { queimaduras de pele. Os cuidados de } \\
\text { enfermagem estão direcionados aos } \\
\text { cuidados com a pele e extremidades, } \\
\text { uso do gelo, sedação e conforto. }\end{array}$ \\
\hline $\begin{array}{l}\text { Prática avançada de } \\
\text { enfermagem em } \\
\text { resposta à } \\
\text { hipotermia } \\
\text { terapêutica }\end{array}$ & 2017 & $\begin{array}{l}\text { Wannemacher } \\
\text { et al. }\end{array}$ & $\begin{array}{l}\text { Determinar se os resultados } \\
\text { obtidos sobre os pacientes } \\
\text { submetidos a hipotermia } \\
\text { terapêutica são melhores com o } \\
\text { acréscimo de enfermeiros } \\
\text { especializados em terapia } \\
\text { hipotérmica à equipe. }\end{array}$ & $\begin{array}{l}\text { Este projeto fornece dados } \\
\text { fundamentais para avaliar } \\
\text { enfermeiros especializados, mostrar a } \\
\text { importância de mantê-los na equipe e } \\
\text { para avaliar dados futuros usando } \\
\text { uma amostra maior. }\end{array}$ \\
\hline $\begin{array}{l}\text { Hipotermia induzida } \\
\text { leve após retorno da } \\
\text { circulação } \\
\text { espontânea }\end{array}$ & 2015 & Hall et al. & $\begin{array}{l}\text { Estudo de revisão da literatura } \\
\text { com objetivo de buscar evidências } \\
\text { mais recentes e relevantes sobre a } \\
\text { hipotermia induzida. }\end{array}$ & $\begin{array}{l}\text { Hipotermia induzida aumenta a taxa } \\
\text { de sobrevivência a longo prazo e } \\
\text { resultado neurológico em pacientes } \\
\text { que tiveram parada cardíaca. } \\
\text { Recuperação funcional } \\
\text { significativamente maior na alta do } \\
\text { que pacientes normotérmicos. } \\
\text { Diminui a mortalidade hospitalar e } \\
\text { proporciona melhora neurológica. }\end{array}$ \\
\hline
\end{tabular}




\begin{tabular}{|c|c|c|c|c|}
\hline $\begin{array}{l}\text { Hipotermia } \\
\text { terapêutica após } \\
\text { parada cardíaca e } \\
\text { retorno da } \\
\text { circulação } \\
\text { espontânea: } \\
\text { é complicado }\end{array}$ & 2014 & Beseda et al. & $\begin{array}{l}\text { Fazer um estudo de caso } \\
\text { associando com todas as fases da } \\
\text { hipotermia terapêutica propostas } \\
\text { pela Guideline da American Heart } \\
\text { Association (AHA). }\end{array}$ & $\begin{array}{l}\text { O paciente parece ter se beneficiado } \\
\text { neurologicamente pela indução da } \\
\text { hipotermia terapêutica pois logo após } \\
\text { ser extubado, o paciente conseguiu } \\
\text { seguir comandos simples. }\end{array}$ \\
\hline $\begin{array}{l}\text { Melhorar os } \\
\text { resultados com } \\
\text { hipotermia } \\
\text { terapêutica }\end{array}$ & 2013 & $\begin{array}{l}\text { Bucher } \\
\text { et al. }\end{array}$ & $\begin{array}{l}\text { Identificar a eficácia da aplicação } \\
\text { da hipotermia terapêutica em } \\
\text { paciente pós parada cardíaca }\end{array}$ & $\begin{array}{l}\text { Paciente selecionado para estudo } \\
\text { com indicação de hipotermia } \\
\text { induzida, após ingestão de corpo } \\
\text { estranho, resultando em obstrução } \\
\text { de vias áreas e subsequente parada } \\
\text { cardíaca. Em internação na UTI e } \\
\text { início rápido de resfriamento, no } \\
\text { terceiro dia de internação, ele se } \\
\text { encontrava acordado e respondia a } \\
\text { comandos simples. No quarto dia o } \\
\text { mesmo foi extubado, alguns déficits } \\
\text { neurológicos leves (fraqueza e fala } \\
\text { lenta), porém, obteve alta no décimo } \\
\text { dia de hospitalização. }\end{array}$ \\
\hline $\begin{array}{l}\text { Hipotermia } \\
\text { terapêutica pós- } \\
\text { parada cardíaca }\end{array}$ & 2012 & Erb et al. & $\begin{array}{l}\text { Discutir eficácia da hipotermia } \\
\text { terapêutica, indicações e } \\
\text { contraindicações para seu uso, } \\
\text { descrever os métodos de indução, } \\
\text { complicações e efeitos adversos } \\
\text { associados e cuidados de } \\
\text { enfermagem específicos ao } \\
\text { paciente submetido a esse } \\
\text { procedimento. Revisar a } \\
\text { fisiopatologia da lesão cerebral } \\
\text { anóxica e discutir a eficácia da HT } \\
\text { na prevenção de sua ocorrência. }\end{array}$ & $\begin{array}{l}\text { Para que a hipotermia seja eficaz, } \\
\text { candidatos devem ser identificados } \\
\text { rapidamente, serem submetidos à HT } \\
\text { logo após a parada cardíaca e } \\
\text { mantida por } 12 \text { a } 24 \text { horas, uma vez } \\
\text { que a temperatura central desejada } \\
\text { foi alcançada. Durante todas as três } \\
\text { fases da hipotermia terapêutica, os } \\
\text { pacientes devem ser avaliados para } \\
\text { tratamentos das complicações e para } \\
\text { sinais de eventos adversos associados } \\
\text { com parada cardíaca. }\end{array}$ \\
\hline $\begin{array}{l}\text { Resfriamento de } \\
\text { superfície após } \\
\text { parada cardíaca: } \\
\text { eficácia, segurança } \\
\text { da pele e eventos } \\
\text { adversos na prática } \\
\text { clínica de rotina }\end{array}$ & 2011 & Jarrah et al. & $\begin{array}{l}\text { Avaliar eficiência e segurança de } \\
\text { um dispositivo indutor de } \\
\text { hipotermia por superfície (Arctic } \\
\text { Sun Temperature Management } \\
\text { System - Medivance Inc., } \\
\text { Louisville, CO USA), dando ênfase } \\
\text { nos eventos adversos e foco nas } \\
\text { complicações de pele. O } \\
\text { dispositivo foi utilizado de } 2006 \text { a } \\
2008 \text { na instituição e essa } \\
\text { avaliação foi feita a partir de uma } \\
\text { extensa base de dados que relata } \\
\text { essas experiências. }\end{array}$ & $\begin{array}{l}\text { Durante a rotina clínica, o dispositivo } \\
\text { analisado teve resultados efetivos na } \\
\text { indução da hipotermia em pacientes } \\
\text { pós-PCR, não sendo frequente a } \\
\text { ocorrência de feridas na pele. } \\
\text { Quando estas ocorreram, eram } \\
\text { estatisticamente relacionadas ao } \\
\text { choque e a baixa função ventricular. } \\
\text { Eventos adversos foram similares a } \\
\text { aqueles reportados rotineiramente } \\
\text { em outros métodos de hipotermia } \\
\text { terapêutica, exceto pela pneumonia } \\
\text { que foi reduzida por antibióticos } \\
\text { profiláticos de rotina. }\end{array}$ \\
\hline
\end{tabular}

Jarrah et al. (2011) destacam somente sobre os mecanismos de resfriamento de superfície (sacos de gelo, cobertores de ar frio ou almofadas), enquanto, Carwel (2018) e Beseda et al. (2014), além de abordarem este método, incluem ainda o mecanismo de resfriamento intravenoso (soro fisiológico frio). Diante desse contexto, Bucher et al. (2013) evidencia que esses métodos de resfriamento são extremamente eficazes na redução de temperatura corporal, introduzidas novas técnicas a cada ano.

Beseda et al. (2014) destaca alguns fatores que devem ser monitorados durante a terapêutica, sendo estes: os sinais vitais (destacando a temperatura), a ventilação (gasometria arterial - usada para monitorar hiperventilação e hipercapnia), glicose (níveis de glicose devem estar adequados), perfusão (perfusão de tecidos adequada deve ser mantida a todo tempo), sinais e sintomas de infecção com supressão de febre por hipotermia e pele. Wannemacher et al. (2017) aponta somente a monitorização da integridade da pele caso o resfriamento seja obtido diretamente pela superfície. 
Sara Kinppa et al. (2020) levanta apontamentos referente a escolha entre as temperaturas 33으 e 36 으, onde se conclui que este parâmetro deve ser escolhido de acordo com a avaliação clínica do paciente, uma vez que é mais eficiente utilizar a temperatura que esteja mais próxima da sua situação atual, o que acarretará em menor risco de complicação. Refere ainda que o protocolo pode ser alterado a qualquer momento, a depender da resposta clínica do paciente ao tratamento. Jarrah et al. (2011), Beseda et al. (2014), Wannemacher et al. (2017), Erb et al. (2012) e Hall (2015) apontam como temperatura indicada para realização da hipotermia induzida 32 a $34^{\circ} \mathrm{C}$, sendo o tempo de resfriamento mantido de 12 a 24 horas.

De acordo com a pesquisa citada por Ern et al. (2012) com os 745 pacientes que foram induzidos a $\mathrm{HT}$, os eventos adversos mais frequentes foram respectivamente pneumonia (48\%), hiperglicemia (37\%), convulsões (24\%) e os demais eventos adversos observados foram hipofosfatemia, hipocalemia, hipomagnesemia, bradicardia e outros. Jarrah et al. (2011), destaca como possíveis eventos adversos e complicações: fissuras na pele, tremores, sangramento, hipertermia de rebote, hiperglicemia, hipocalemia e infecção (pneumonia). Assim como Jarrah et al. (2011), Beseda et al. (2014) traz tremores e risco aumentado para pneumonia como possíveis evoluções da terapêutica, incluindo a sepse. Hall (2015) cita complicações relacionadas a hiperglicemia e alterações de instabilidade hemodinâmica. Corrêa et al. (2018) aponta tremores, bradicardia, hipotensão e queimaduras de pele.

Segundo Bucher et al. (2013) “A hipotermia terapêutica não é apropriada para pacientes que são grávidas, pacientes com trauma ou sangramento descontrolado, pacientes que tiveram cirurgias, pacientes com bradicardia grave, estado cognitivo pré-mórbido mínimo, ou hemorragia intracraniana". Erb et al. (2012) cita que é a HT é contra-indicada em pacientes com lesão traumática, sangramento não compressível ativo ou um diagnóstico de hemorragia intracraniana. Ao contrário do que os autores expressaram, Beseda et al. (2014) expõe apenas que precauções devem ser tomadas antes de induzir HT em pacientes diagnosticados com infecção sistêmica ou sepse.

Vale ressaltar que o papel do enfermeiro é de extrema importância nas fases da hipotermia terapêutica que são: identificação do paciente, indução, manutenção e reaquecimento, uma vez que exigem monitorização intensa, conhecimento científico e avaliação da progressão do quadro, bem como de possíveis eventos adversos e/ou complicações. Carwel (2018) destaca que ainda não é possível definir o melhor método / protocolo de resfriamento, bem como a duração do mesmo devido à escassez de evidência científica e aplicabilidade da HT no ambiente hospitalar.

\section{CONCLUSÕES}

O estudo realizado evidenciou que a hipotermia terapêutica é eficaz e benéfica ao paciente em pós parada cardiorrespiratória, independente da ocorrência de eventos adversos e possíveis complicações, considerando que a maioria destes podem ser evitados com intervenções preventivas e monitorização dos sinais vitais e hemodinâmicos de forma rigorosa pelos profissionais enfermeiros.

Devido à alta variação nos resultados em decorrência da resposta de cada quadro clínico, esse 
método acaba sendo subutilizado e, consequentemente, ocasionando inconsistência de informações na literatura, dificultando o esclarecimento do manejo dos profissionais enfermeiros. Nota-se, ainda, escassez de conteúdos técnico-científicos em relação a protocolos definidos e, até mesmo, o conhecimento da equipe de enfermagem sobre o método estudado. Conclui-se que é de suma importância o desenvolvimento de estudos diante deste contexto para amplificar evidências e fortalecer as responsabilidades do profissional enfermeiro.

\section{REFERÊNCIAS}

ABREU, A.; DUQUE, A.; PAULINO, C.; BRITO, J.; SILVESTRE, J.; PEREIRA, J. G.. Papel neuroprotetor da hipotermia terapêutica pós paragem cardio-respiratória. Rev. bras. ter. intensiva, v.23, n.4, p.455-461. DOI http://dx.doi.org/10.1590/S0103-507X2011000400010

AHA. American Heart Association. Destaques das Diretrizes da American Heart Association. AHA, 2015.

BESEDA, R.; SMITH, S.; VEENSTRA, A.. Therapeutic Hypothermia After Cardiac Arrest and Return of Spontaneous Circulation: It's Complicated. Crit Care Nurs Clin North Am, v.26, n.4, 2014. DOI https://doi.org/10.1016/j.ccell.2014.08.001

BUCHER, L.; BURUSCHKIN, R.; KENYON, D. M.; STENTON, K.; TRESEDER, S.. Improving outcomes with therapeutic hypothermia. Nurse Pract, v.38, n.1, p.49-52, 2010. DOI https://doi.org/10.1097/01.NPR.0000422209.77303.21

CARWELL, M.. targeted temperature management for improved outcomes: are we there yet?. Crit Care Nurs Q, v.41, n.2, p.102-108, 2021. DOI https://doi.org/10.1097/CNQ.0000000000000199

CASTRO, J. F.. Fatores dificultadores que influenciam na utilização da hipotermia terapêutica como medida profilática pós-parada cardiorrespiratória nas unidades de terapia intensiva. Belo Horizonte: Universidade Federal de Minas Gerais, 2014.

CORRÊA, L. V. O.; SILVEIRA, R. S.; MANCIA, J. R.; CORRÊA, N. L.; REINHARDT, I. M. S.; LUNARDI, V. L.. Hipotermia terapêutica: efeitos adversos, complicações e cuidados de enfermagem. Enfermagem em Foco, v.9, n.4, p.56-59, 2018. DOI: https://doi.org/10.21675/2357-707X.2018.v9.n4.2136

ERB, J. L.; HRAVNAK, M.; RITTENBERGER, J. C.. Therapeutic hypothermia after cardiac arrest. Am J Nurs, v.112, n.7, p.38-44, 2021. DOI: https://doi.org/10.1097/01.NAJ.0000415959.85050.1a

HALL, H.. Mild induced hypothermia after return of spontaneous circulation. Emerg Nurse, v.23, n.2, p.27-31,
2021. DOI: https://doi.org/10.7748/en.23.2.27.e1415

JARRAH, S.; DZIODZIO, J.; LORD, C.; FRASER, G. L.; LEE, L.; RIKER, R. R.. Surface cooling after cardiac arrest: effectiveness, skin safety, and adverse events in routine clinical practice. Neurocrit Care, 14, n.3, p.382-388, 2011. DOI: https://doi.org/10.1007/s12028-011-9506-y

KEEBLE, T. R.; GOSSIP, M.; CORDOZA, M.; DECKARD, M.; WATSON, N.. Temperature management in nursing care. ther hypothermia temp manag, Mary Ann Liebert, Inc, v.8, n.3, p.131-135, 2021. DOI: https://doi.org/10.1089/ther.2018.29049.tjk

KNIPPA, S.; BUTLER, J.; JOHNSON, L.; PERMAN, S. M.. The cold truth about postcardiac arrest targeted temperature management: $33^{\circ} \mathrm{C}$ vs. $36^{\circ} \mathrm{C}$. Nursing, v.50, n.10, p.24-30, 2021. DOI

https://doi.org/10.1097/01.NURSE.0000697148.62653.1a

OLIVEIRA, F. M. B.; LIMA, I. R.; SPAZIANE, A. O.; SPAZIANE, L. C.; SILVA, D. P. T.. Ação da hipotermia terapêutica e seus efeitos em pacientes reanimados pós- parada cardiorrespiratória: uma revisão de literatura. Brazilian Journal of health Review, v.3, p.1384-1392. DOI: https://doi.org/10.34119/bjhrv3n2-004

PEDROSA, A. T. S.; CAVAlCANTI, A. L. A.; CAETANO, A. C.; BEZERRA, A. K. F.; BEZERRA, A. M. F. A.; SENA, A. R. Percepção dos enfermeiros quanto ao protocolo de hipotermia terapêutica pós parada cardiopulmonar. Prevenção e Promoção da Saúde 2, v.2, n.27, 2021. DOI: https://doi.org/10.22533/at.ed.281190912

ROCHA, I. K. N.; GUIMARÃES, C. A. A.; OLIVEIRA, C. G. S.. Hipotermia terapêutica em pacientes pós parada cardiorrespiratória: uma revisão integrativa. Ciências Biológicas e da Saúde, v.4, n.2, p.203-218, 2017.

WANNEMACHER, J.; TSCHANNEN, D.; BIERY, K.; ARSLANIANENGOREN, C.. advanced practice registered nurses on therapeutic hypothermia response teams. AACN Adv Crit Care, v.28, n.4, p.332-341. DOI: https://doi.org/10.4037/aacnacc2017708

A CBPC - Companhia Brasileira de Produção Científica (CNPJ: 11.221.422/0001-03) detém os direitos materiais desta publicação. Os direitos referem-se à publicação do trabalho em qualquer parte do mundo, incluindo os direitos às renovações, expansões e disseminações da contribuição, bem como outros direitos subsidiários. Todos os trabalhos publicados eletronicamente poderão posteriormente ser publicados em coletâneas impressas sob coordenação da Sustenere Publishing, da Companhia Brasileira de Produção Científica e seus parceiros autorizados. Os (as) autores (as) preservam os direitos autorais, mas não têm permissão para a publicação da contribuição em outro meio, impresso ou digital, em português ou em tradução. 